\title{
Evaluation of Marbofloxacin in Beagle Dogs After Oral Dosing: Preclinical Safety Evaluation and Comparative Pharmacokinetics of Two Different Tablets
}

\author{
Zhixin Lei ${ }^{1,2,3}$, Qianying Liu ${ }^{1,2,3}$, Bing Yang ${ }^{1,2}$, Haseeb Khaliq ${ }^{2}$, Saeed Ahmed ${ }^{2,3}$, \\ Bowen Fan ${ }^{1,2}$, Jiyue $\mathrm{CaO}^{2,3 *}$ and Qigai $\mathrm{He}^{1 *}$ \\ ${ }^{1}$ State Key Laboratory of Agriculture Microbiology, College of Veterinary Medicine, Huazhong Agriculture University, Wuhan, \\ China, ${ }^{2}$ Department of Veterinary Pharmacology, College of Veterinary Medicine, Huazhong Agricultural University, Wuhan, \\ China, ${ }^{3}$ National Reference Laboratory of Veterinary Drug Residues and MAO Key Laboratory for Detection of Veterinary \\ Drug Residues, Huazhong Agriculture University, Wuhan, China
}

OPEN ACCESS

Edited by:

Yurong Lai,

Gilead (United States), United States

Reviewed by:

Constantin Mircioiu,

Carol Davila University of Medicine and Pharmacy, Romania

James Whiteford McBlane,

Medicines and Healthcare Products Regulatory Agency, MHR,

United Kingdom

*Correspondence:

Jiyue Cao

caojiyue2@163.com

Qigai He

he628@mail.hzau.edu.cn

Specialty section

This article was submitted to Drug Metabolism and Transport,

a section of the journal

Frontiers in Pharmacology

Received: 17 January 2018

Accepted: 16 March 2018

Published: 10 April 2018

Citation:

Lei Z, Liu Q, Yang B, Khaliq H,

Ahmed S, Fan B, Cao J and He Q (2018) Evaluation of Marbofloxacin in

Beagle Dogs After Oral Dosing

Preclinical Safety Evaluation and Comparative Pharmacokinetics of Two Different Tablets.

Front. Pharmacol. 9:306. doi: 10.3389/fphar.2018.00306
The current study evaluates a tested marbofloxacin tablet (MBT) (Petsen), in terms of bioavailability and pharmacokinetics (PK) in a comparison of the commercialized and standard tablet (Marbocyl) in beagle dogs. Four different bacterial species were selected for the determination of the minimal inhibitory concentration (MIC) against marbofloxacin (MBF). Target animal safety studies were conducted with a wide spectrum of dosages of Petsen. Pharmacokinetics and bioavailability of Petsen were observed after the oral administration of a recommended dosage of $2 \mathrm{mg} / \mathrm{kg}$. The $\mathrm{MIC}_{90}$ of $\mathrm{MBF}$ against Staphylococcus aureus, Escherichia coli, Pasteurella multocida, and Streptococcus were 2.00, 4.00, 0.25 , and $0.50 \mu \mathrm{g} / \mathrm{ml}$, respectively. These results showed that the MBT has an expected antimicrobial activity in vitro. The main parameters of $t_{1 / 2 \beta}, \mathrm{Cl}_{\mathrm{b}}, \mathrm{AUC}_{0-\infty}$, $C_{\max }$, and $K_{e}$ were $22.14 \mathrm{~h}, 0.15 \mathrm{~L} / \mathrm{h}, 13.27 \mu \mathrm{g} . \mathrm{h} / \mathrm{ml}, 0.95 \mu \mathrm{g} / \mathrm{ml}, 0.09 \mathrm{~h}^{-1}$, and $16.47 \mathrm{~h}$, $0.14 \mathrm{~L} / \mathrm{h}, 14.10 \mu \mathrm{g} . \mathrm{h} / \mathrm{ml}, 0.97 \mu \mathrm{g} / \mathrm{ml}, 0.11 \mathrm{~h}^{-1}$ after the orally administrated Petsen and Marbocyl, while no biologically significant changes and toxicological significance have been found by their comparison. These findings indicate that the Petsen had a slow elimination, high bioavailability and kinetically similar to the commercialized Marbocyl. Furthermore, no statistically significant differences were distinguished on the continuous gradient dosages of 2, 6, and $10 \mathrm{mg} / \mathrm{kg}$ in the term of the clinical presentation. The present study results displayed that the tested MBT (Petsen) was safe, with limited toxicity, which was similar to the commercialized tablet (Marbocyl), could provide an alternative MBT as a veterinary medicine in beagle dogs.

Keywords: fluoroquinolones, marbofloxacin, pharmacokinetics, Beagle dogs, bioavailability, toxicity

\section{BACKGROUND}

Marbofloxacin (MBF), belongs to the third-generation synthetic fluoroquinolone antibiotic formulated especially for the veterinary field. Due to its wide range of bactericidal activity, MBF is mostly used against Mycoplasma, Gram-negative, and some of the Gram-positive pathogens (Sidhu et al., 2011; Tohamy and El-Gendy, 2013). It is administered orally or parenterally for the treatment 
of gastrointestinal and respiratory diseases in pigs and cattle, and has a high bioavailability, near to $100 \%$ (Committee for Veterinary Medicinal Products, 2009a; Ding et al., 2010; Tohamy and El-Gendy, 2013; Shan et al., 2014). Due to its broad spectrum it is efficient against canine pathogenic bacteria such as: Streptococcus spp., Proteus spp., Staphylococcus spp., and Escherichia coli, and is permitted for the treatment of pet animals at a dosage level of $2.0 \mathrm{mg} / \mathrm{kg}$ body weight (b.w.) once a daily, by an oral administration (Soussy et al., 1989; Unmack, 1990; Spreng et al., 1995; Thomas et al., 1997; Paradis et al., 2001).

In a 13 -week repeat-dose study with an oral dosage of 1,4 , and $40 \mathrm{mg} / \mathrm{kg}$ b.w. MBF in adult dogs, testicular tubular atrophy was observed in only one of the dogs given a dose of $40 \mathrm{mg} / \mathrm{kg}$ b.w.; no effects were observed at doses of below than $40 \mathrm{mg} / \mathrm{kg}$. These findings propose that MBF has a low toxicity and a broad dose range (Committee for Veterinary Medicinal Products, 2009b). Additionally, adverse reactions are rarely described in veterinary clinical trials in which MBF has been evaluated (Cotard et al., 1995; Carlotti et al., 1998, 1999; Frazier et al., 2000). Further, MBF has been demonstrated to be a safe for the use in dogs even if used at three times the recommended dose, continuously for 3 months (Bousquetmelou et al., 1997). Inappetence decreased activity, and vomiting were the most commonly observed mild signs. However, there are no available studies of intensive doses from 4 to $40 \mathrm{mg} / \mathrm{kg}$ b.w., and a few safety evaluations regarding the toxicity in dogs administered marbofloxacin tablet (MBT).

The pharmacokinetics (PK) actions of MBF have been studied in various animals such as cows, goats, sheep, pigs, cats, and dogs (Waxman et al., 2001; Schneider et al., 2004; Albarellos et al., 2005; Ding et al., 2010; Sidhu et al., 2010a,b, 2011); these studies showed that MBF was widely and rapidly distributed in tissue, with a high bio-distribution in the peripheral tissue and plasma, and showing nearly $100 \%$ bioavailability. However, few studies on the PK of MBF in dogs were studied and the previous reports have revealed that $\mathrm{MBF}$ has the $\mathrm{PK}$ features such as good absorption after oral/parenteral supplementation, higher amounts in tissue than plasma, and weak binding to the plasmatic proteins $(<10 \%)$ (Schneider et al., 1996; Haritova et al., 2006; Andraud et al., 2011; Sun et al., 2015). MBF is widely distributed throughout the animal's body, which can result in 1.6

Abbreviations: MBF, Marbofloxacin (the active ingredient in marbofloxacin powder); MBT, marbofloxacin tablet; PK, pharmacokinetics; EMA, European Medicines Agency; HPLC, high performance liquid chromatography; TSB, tryptic soy broth, TSA, tryptic soy agar; MIC, minimal inhibitory concentration; CLSI, Clinical and Laboratory Standards; OECD, Economic Cooperation and Development; FDA, Food and Drug Administration; RBC, red blood cell count; HGB, hemoglobin concentration; WBC, white blood cell count; HCT, hematocrit; PLT, blood platelet count; Urine analysis included ketone bodies; GLU, glucose; BIL, bilirubin; URO, urobilin; BLD, occult blood; PRO, protein; NIT, nitrite; ALP, alkaline phosphatase; AST, aspartate aminotransferase; ALT, alanine aminotransferase; ALB, albumin; TP, total protein; GLU, glutamate; BUN, blood urea nitrogen; CHOL, cholesterol; CREA, creatinine; CK, creatine kinase; TG, triglyceride; TBIL, total bilirubin; K, potassium; Na, sodium; Ca, calcium; CI, chloride; P, inorganic phosphorus; LLOD, the lower limit of detection; LLOQ, the lower limit of quantitation; $K_{e}$, elimination rate of constant; $t_{1 / 2 \beta}$, half-life of elimination; $\mathrm{Cl}_{\mathrm{b}}$, the total body clearance; $\mathrm{MRT}$, mean residence time; $\mathrm{AUC}_{0-\infty}$, area under curve from 0 to $\infty$; $T_{\max }$, time to the concentration peak; $C_{\max }$, the concentration in the peak; F, biovailability; Petsen (the test marbofloxacin tablet); Marbocyl (the reference marbofloxacin tablet). times more drug concentration in skin comparing to the plasma of dogs. Moreover, MBF plasma concentrations can sustain above the minimal inhibitory concentration (MIC) ( $>24 \mathrm{~h}$ ) longer than the dose density (Schneider et al., 1996). As MBT is a new formulation for treatment in pets, few PK properties are available in previous reports. In the previous plasma PK study, 1.25 and $2.5 \mathrm{mg}$ MBTs (Marbocyl) were performed in beagle dogs (MBT, FDA, Marbocyl), but the recommended dosage $(2 \mathrm{mg} / \mathrm{kg})$ by EMA was used in this study. Compared with the Marbocyl, the MBT (Petsen) in this study was compared the toxicity and PK data like bioequivalence in dogs.

Bioequivalence studies support complementary applications in the formulation, route of administration, or manufacturing process that may affect bioavailability (Ozdemir and Yildirim, 2006; Zaid et al., 2017). The criteria for bioequivalence are formulated by their respective organizations, and there are relevant guidelines from regulatory bodies in Europe and the United States. According to guidelines two products are tested in order to prove that active ingredients are available at the site of drug action, following similar assimilation rate and extent (Listed, 1998; Rockville, 2000; Chen et al., 2001; U. S. Food and Drug Administration, 2003; Davit et al., 2016). The similarity is defined by acceptable limits of differences between the pharmacokinetic parameters of compared products (Alp, 2009; Galgatte, 2014; Kaushal et al., 2016). In other words, demonstrating bioequivalence between two drug products means that the same rate and extent of absorption of the active components is assured. Mathematical characterization is: " $\mathrm{A}$ tested drug $\mathrm{T}$ is bioequivalent with a reference drug $\mathrm{R}$ if the $90 \%$ confidence interval (CI) for ratios of means $\mu$ of main pharmacokinetic parameters - area under the curve (AUC) and maximum concentrations $C_{\max }$ are included in the $0.8-1.25$ interval" (Gherghiceanu et al., 2016). In fact the quantitative, statistical rule implies that even products with different half time of adsorption and halftime of elimination can be bioequivalent.

In this study, we wished to compare Petsen, a product in development which contains MBF, with Marbocyl, which is a marketed veterinary product, in China, containing MBF. Petsen has been developed for veterinary use in treating cats and dogs: both are presented as tablets with $20 \mathrm{mg}$ MBF. Moreover, the drug content and key excipients were similar to the referenced MBT (Marbocyl). In this study, the aim was to assess the evaluation of $\mathrm{MBF}$ in beagle dogs after oral dosing, including the preclinical safety evaluation and comparative PK of two different tablets the tested Petsen and the reference formulation Marbocyl. The findings of this study could provide an alternative product for use of MBT in veterinary medicine.

\section{MATERIALS AND METHODS Chemicals and Bacteria}

The standard substance MBF (100.3\% purity, NO. 201104005) was formulated and supplied by Wuhan Huishen Biotechnology Co., Ltd., The MBT (Petsen) (20 mg/tablet; NO.20110505) containing $71.4 \% \mathrm{MBF}$ per tablet, were formed and supplied by Wuhan Longyu Biotechnology Co., Ltd. The all of the chemical agents used for this analysis were of high-performance liquid 
chromatography (HPLC) grade, and other organic solvents were of analytical grade. Marbocyl $(20 \mathrm{mg} /$ tablet $)$ provided by the French company Vetoquionol S.A. The standard substance MBF was prepared under sterile conditions by addition of a $2 \%$ sterilized aqueous solution of acetic acid into a sterile injectable solution, with the concentration of $20 \mathrm{mg} / \mathrm{mL}$ by the authors in this study. To test the susceptibility of bacteria to MBF, each isolate was sub-cultured at least three times in tryptic soy broth (TSB) and tryptic soy agar (TSA; Qingdao Hai Bo Biological Technology Co., Ltd., Shangdong, China) containing 5\% newborn calf serum (Zhejiang Tianhang Biotechnology Co., Ltd., Zhejiang, China).

\section{Bacteria Strain Isolation}

Four kinds of bacteria (Staphylococcus aureus, E. coli, Pasteurella multocida, and Streptococcus) with 50 isolates were selected to determine the MIC of MBF. Each kind of bacteria including 50 strains was isolated from beagle dogs from various Chinese provinces including Hubei, Anhui, Jiangxi, Guangzhou, and Sichuan between 2016 to 2017 years. E. coli ATCC 25922 strain was selected to be used as a reference isolate for antibiotic susceptibility determination. Before testing the MIC, each of isolate was sub-cultured at least three times in TSB or TSA.

\section{Animals}

Thirty-six healthy male and female beagle dogs, weighing between 8.0 and $10.0 \mathrm{~kg}$, were selected from the Center of Laboratory Animals of Hubei Province (Wuhan, PR China) and were prepared for PK studies. The animals (dogs) were housed separately in cages under a $12 \mathrm{~h}$ light/dark cycle and were offered ad lib food and water during this experiment.

Animals did not receive any antimicrobial treatment for 14 days before the experiments. These animals were deemed to be normal and clinically healthy after having a regular body checkup and were thus used for this experiment (Lei et al., 2017c).

The study was ratified by Ethical Committee of Huazhong Agricultural University, Faculty of Veterinary Medicine. All the experiments involving animals were accompanied in accordance with the Guide for the Care and Use of Laboratory Animals of Hubei Provincial Laboratory Animal Public Service Center (permit number SYXK 2013-0044).

\section{Antimicrobial Susceptibility Testing}

Determination of MBF susceptibility against the four kinds of bacteria was executed using agar dilution technique, according to Clinical and Laboratory Standards (CLSI) guidelines in the previously described study (Lei et al., 2017b,c). Strains (2-4 $\mu 1$, about $10^{8} \mathrm{CFU} / \mathrm{ml}$ ) were administrated onto TSA agar plates having newborn calf serum, with two-fold serial dilutions of MBF $(0.0625-32 \mu \mathrm{g} / \mathrm{ml})$. When the MIC values of isolates were over $32 \mu \mathrm{g} / \mathrm{ml}$, the MBF concentrations in TSA were expanded for detecting. Strain plates were incubated at $37^{\circ} \mathrm{C}$ for $48 \mathrm{~h}$. MICs were identified as the lowest concentrations of drug that caused the growth inhibition. The MIC-value of E. coli (ATCC 25922) to chloramphenicol was used to verify the results of the susceptibility testing.

\section{TARGET ANIMAL SAFETY EVALUATION}

\section{Experimental Design}

Twenty-four beagle dogs (50\% males) weighing $8-10 \mathrm{~kg}$ and aged 12-14 months old, were selected for inclusion in this study. Dogs were randomly assigned to four groups according to Petsen dose administration. According to the Guiding Principles of Veterinary Drug Research and Development Technology of China, and the Food and Drug Administration (FDA) (Kux, 2011; Shuren, 2012), the dogs in each group were orally administered $0,2,6$, or $10 \mathrm{mg} / \mathrm{kg}$ of Petsen daily, respectively, for 40 continuous days. All dogs in each group were anesthetized with pentobarbital sodium and euthanized at 22-24h after their last dose. Dogs in the control and high dose groups were selected to investigate the change in visceral organs after day 40. This study complied with the Technical Guidelines of Veterinary Drug research and Good Laboratory Practice Regulations of China (Good Laboratory Practice Regulations of China, 2012).

\section{Clinical Observations}

Throughout the study, we observed Beagle dogs at least twotimes/day to determine the mortality, morbidity, severity, and duration of any behavior change, evidence of toxicity, as well as to observe the general appearance and abnormalities. Detailed animal health examinations, including temperature, body weight, and food consumption were performed on each animal on day 0 , 14 , and at the termination of the study (day 40).

\section{Hematology Analysis}

Blood and urine were collected from all dogs in each group, for hematological and urine analysis, which was by use of a Coulter HmX Hematology Analyzer (Beckman Coulter Inc., Fullerton, CA, USA) and a UA-66 Urine Analyzer (Shanghai TianChen Technology Inc., China). Blood and urine were collected on day 0,14 , and 40. Hematological evaluations included hemoglobin concentration (HGB), red blood cell count (RBC), white blood cell count (WBC), hematocrit (HCT), and blood platelet count (PLT). Urine analysis included ketone bodies (KET), glucose (GLU), pH, bilirubin (BIL), urobilin (URO), occult blood (BLD), protein (PRO), nitrite (NIT).

\section{Serum Biochemistry}

Serum biochemistry was performed with a Synchron Clinical System CX4 (Beckman Coulter, Brea, CA USA) under the manufacturer's guidelines (Beijing Leadman Biochemistry Technology Co. Ltd., Bejing, China). The serum biochemistry evaluations included aspartate aminotransferase (AST), alanine aminotransferase (ALT), alkaline phosphatase (ALP), albumin (ALB), total protein (TP), glutamate (GLU), cholesterol (CHOL), blood urea nitrogen (BUN), creatinine (CREA), triglyceride (TG), creatine kinase (CK), total bilirubin (TBIL), potassium $(\mathrm{K})$, sodium $(\mathrm{Na})$, chloride $(\mathrm{CI})$, inorganic phosphorus $(\mathrm{P})$, and calcium $(\mathrm{Ca})$.

\section{Histopathological Examinations}

The main organs of each animal, including heart, liver, spleen, lungs, and kidneys, were weighed separately. Organ weight/100 g 
body weight was determined on the basis of fasted animal's body weight. The tissues from these organs were kept in $10 \%$ neutral buffered formalin until testing. Histopathological study was conducted with routine paraffin-embedding method and sections of $5 \mu \mathrm{m}$ thickness stained with hematoxylin-eosin were observed with light microscopy to evaluate morphology.

\section{Pharmacokinetics and Bioequivalence Study \\ Experimental Design}

A crossover design was used. Twelve beagle dogs were divided into two groups, with half males and females in each group. One group received a single oral administration of Marbocyl, while the other group received oral administration of Petsen by gavage; the dosage for both groups was $2 \mathrm{mg} / \mathrm{kg}$. After a 14-day washout period, dogs in the two groups were given the alternate treatment, either Marbocyl or Petsen at $2 \mathrm{mg} / \mathrm{kg}$. After another 14-day washout period, 6 beagle dogs were selected from these 12 and given a single i.v. injection of an aqueous solution of the base form of MBF at the same dose. Blood samples were collected at predetermined times as follows: 0 , 10 , 30, and $45 \mathrm{~min}, 1,1.5,2,2.5,3,4,6,8,12,16,24,36$, 48,60 , and $72 \mathrm{~h}$ following the administration of the three drug formulations.

Blood samples $(2.0 \mathrm{~mL})$ were collected by injecting a 7 -gage needle into the forelimb cephalic vein or the hind leg saphenous vein and letting the blood drop into a $5 \mathrm{~mL}$ heparinized centrifuge tube. Samples obtained were centrifuged at 3,000 rpm/min for about $15 \mathrm{~min}$. The plasma was immediately removed and stored at $-20^{\circ} \mathrm{C}$ until analyzed.

\section{Plasma Treatment and HPLC Conditions}

Plasma samples were thawed to room temperature and MBF in the plasma was extracted. A $0.2 \mathrm{~mL}$ plasma sample was placed into a $5 \mathrm{~mL}$ polypropylene centrifuge tube; $2 \mathrm{~mL}$ chloroform extractant was added. This blend was horizontally vortexed for $5 \mathrm{~min}$ and later centrifuged for $6 \mathrm{~min}$ at $12,000 \mathrm{rpm}$. The separated lower layer was shifted into $10 \mathrm{~mL}$ centrifuge tube and desiccated at $45^{\circ} \mathrm{C}$ under a nitrogen stream. The residue was redissolved in $200 \mu \mathrm{L}$ of a $2 \%$ aqueous solution of acetic acid. This aqueous solution was centrifuged for $5 \mathrm{~min}$ at 5,000 rpm and the supernatant was collected to be analyzed.

Agilent 1100 series equipment was used as the HPLC system, with the variable wavelength indicator (Agilent 1100, G131460086). The MBF drug detection was performed at $295 \mathrm{~nm}$ using an ultraviolet detector. An automatic injection of $25 \mu \mathrm{L}$ was measured on an Agilent ZORBAX Extend-C18 stainless steel column $(250 \times 4.6 \mathrm{~mm}, 5 \mu \mathrm{m})$. The mobile phase was acetonitrile (A) and $1 \%$ formic acid aqueous solution (B) $(75: 25, \mathrm{v} / \mathrm{v})$ with a flow rate of $1.0 \mathrm{~mL} / \mathrm{min}$.

\section{HPLC Method Validation}

This method was confirmed for plasma, and a standard calibration curve was prepared with plasma concentrations of $5,0.5,0.05$, and $0.02 \mu \mathrm{g} / \mathrm{mL}$. Linearity was determined by the standard curve and the precision, accuracy, and recovery were calculated between the standard substance and treated MBF in plasma. The lower limit of detection (LLOD) and the lower limit of quantitation (LLOQ) of MBF were defined as the drug concentrations ensuing in a peak height of three-times, and ten-times, the signal noise, respectively.

\section{Pharmacokinetic and Bioequivalence Analysis}

The pharmacokinetic examination was executed by WinNonlin software. Theoretical curves and experimental data were plotted semi-logarithmical and examined with the naked eye. Selection of the best model was performed using Akaike's Information Criterion (Sandulovici et al., 2009). PK parameters were determined for each individual animal, and the routes of administration were compared.

\section{STATISTICAL ANALYSIS}

Analysis of variance (ANOVA) was applied to compare the pharmacokinetic parameters of the formulations on the test preparation with the reference ones (Pfaller et al., 2010; Government of Canada HC, 2014). $T_{\max }$ association was achieved with a Wilcoxon signed rank test. Parametric 90\% CIs of the mean of test/reference ratios of $\mathrm{AUC}_{0-\infty}$ and $C_{\max }$ were calculated using the residual variance of ANOVA with the assumption of a multiplicative model. Confidence intervals were measured by SPSS analysis (IBM, USA).

MIC $_{90}$ was calculated using SPSS software, and statistical analyzes were performed using Student's $t$-tests, for betweengroup comparisons of the parameters. The $p<0.05$ was considered to indicate a statistically significant difference.

\section{RESULTS}

\section{MIC Distributions of the Four Kinds of Bacteria}

The MIC distributions of MBF to the four kinds of bacteria are presented in Figure 1. The values of MIC ranged from 0.03 to $4.00 \mu \mathrm{g} / \mathrm{ml}$, except for $E$. coli, which ranged from 0.25 to $16.00 \mu \mathrm{g} / \mathrm{ml}$. The values of $\mathrm{MIC}_{90}$ of $\mathrm{MBF}$ against S. aureus, E. coli, P. multocida, and Streptococcus were 2.00, 4.00, 0.25 , and $0.50 \mu \mathrm{g} / \mathrm{ml}$, respectively. These findings indicated that these four kinds bacteria were sensitive to MBF, according to the CLSI M100-S23 guide document. Moreover, these results revealed that $\mathrm{MBF}$ had the excepted antimicrobial activity in vitro. MBF displayed a concentration-dependent killing action.

\section{Target Animal Safety Evaluation Clinical Signs and Mortality}

In the MBF group, all the dogs survived, and no significant differences in coat condition, behavior, or mental condition were observed, in comparison with the control group. Body temperatures from the dogs in the low $(2 \mathrm{mg} / \mathrm{kg})$, middle $(6$ $\mathrm{mg} / \mathrm{kg})$, and high $(10 \mathrm{mg} / \mathrm{kg})$ dose groups were similar to each other, and ranged from 38.05 to $38.26^{\circ} \mathrm{C}$; see Figure 2. Moreover, there were non-significant changes in feed consumption (14.72$16.54 \mathrm{~kg})$ and body weight $(8.96-10.44 \mathrm{~kg})$ between the high, middle, low and dose groups and the control group $(p>0.05)$ 

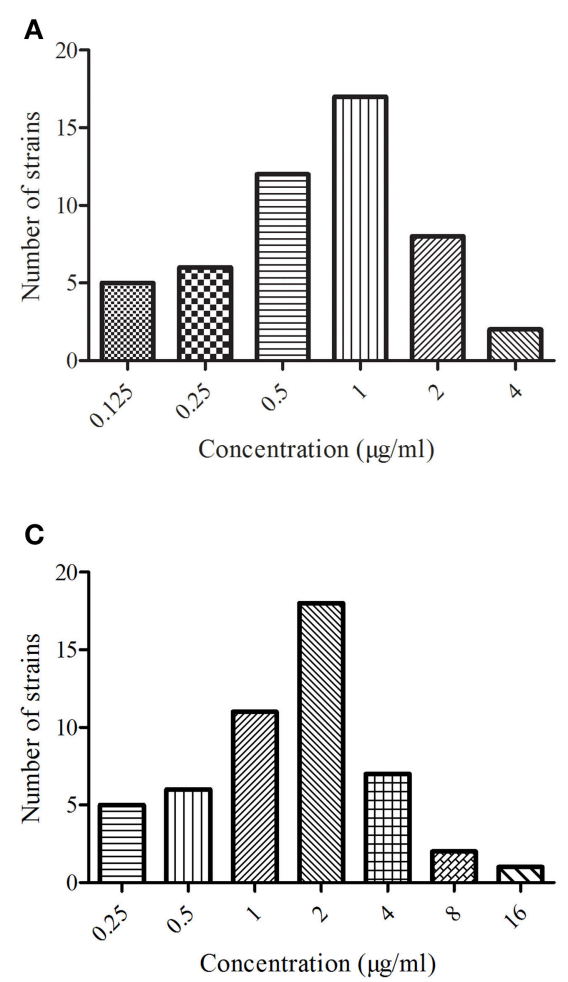

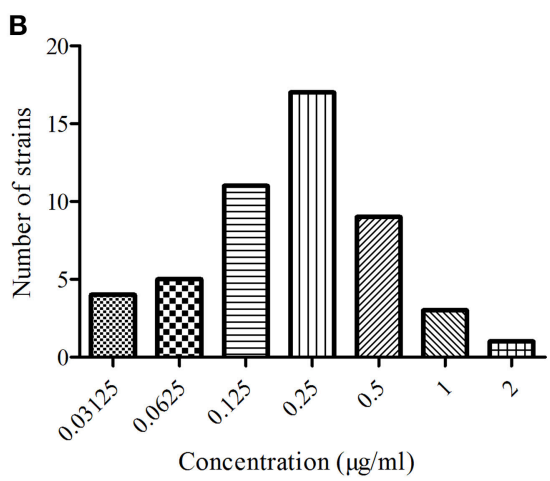

D

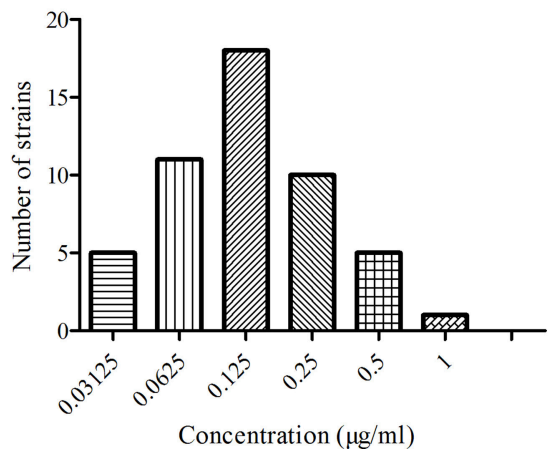

FIGURE 1 | The MIC of marbofloxacin (Petsen) in four kinds of bacteria. (A) Represented MIC distribution of Staphylococcus aureus, (B) represented MIC distribution of Escherichia coli, (C) represented MIC distribution of Pasteurella multocida, (D) represented MIC distribution of Streptococcus.

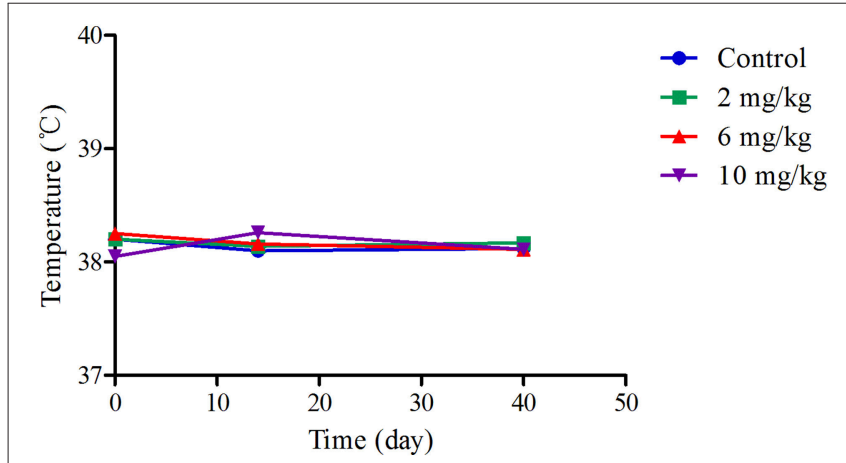

FIGURE 2 | The mean of temperature and body weight in the 40 days feeding study. (A) Represented the mean of temperature.

at day 1, day 14, and day 40 of this study; see Supplemental Table 1 .

\section{Hematological Examination}

At day 1, 14, and 40, HGB, RBC, WBC, HCT, and PLT were tested; the results are presented in Table 1. There were no significant differences $(p>0.05)$ in these indicators between the low, middle, and high dose groups and the control group $(p>0.05)$. However, PLT was decreased and WBC was increased in the 6 and $10 \mathrm{mg} / \mathrm{kg}$ treatment groups (Table 1).

\section{Serum Biochemical Analysis}

The results of serum biochemical analysis were non-significant ( $p>0.05$ ) between the low, middle, high dose treatment groups, and control group excluding TBL, ALT, $\mathrm{Na}^{+}$, and AST which were significantly decreased, and ALP and BUN which were significantly raised $(P<0.05)$. These findings can be found in Table 2. However, these were not biologically significant changes and not biologically significant changes and these values did not fall outside the reference ranges.

\section{Histopathological and Organ Examination}

At $22 \mathrm{~h}$ after the last dose, the relative weights of the main organs (liver, heart, spleen, lungs, and kidneys) were calculated and are shown in Table 3. As compared to the control group, there were no significant differences in the low, middle, and high dose treatment groups. There were no histopathological findings in the organs examined. Articular cartilage from control dogs and dogs given $10 \mathrm{mg} / \mathrm{kg} \mathrm{MBF}$ was investigated under microscopic examination; no differences were seen (see Figure 3).

\section{HPLC Method Validation}

The plasma limit of detection (LLOD) and limit of quantitation (LLOQ) of MBF was 0.02 and $0.05 \mu \mathrm{g} / \mathrm{mL}$, respectively; see Figure 4. The proposed method of HPLC was suitable for MBF quantification in plasma. The recovery of MBF in plasma samples was higher than $85 \%$. The intra-assay coefficients of variation 

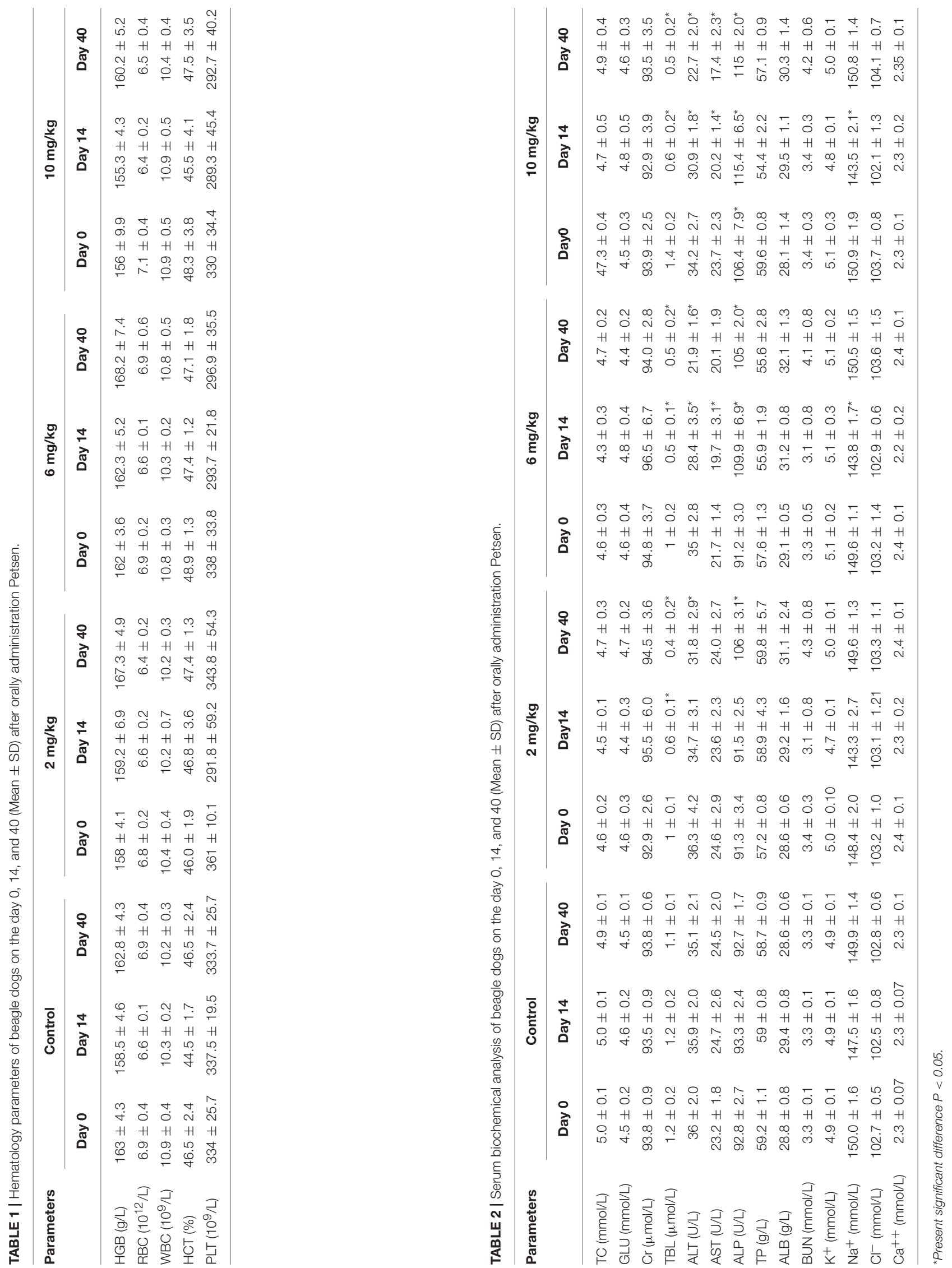
TABLE 3 | Relative weight of main organ in beagle dogs.

\begin{tabular}{lcccc}
\hline Organs & Control (\%) & $\mathbf{2 ~} \mathbf{~ g} / \mathbf{k g}(\%)$ & $\mathbf{6 ~} \mathbf{~ g} / \mathbf{k g}(\%)$ & $\mathbf{1 0 ~} \mathbf{~ g} / \mathbf{k g}(\%)$ \\
\hline Heart & $0.894 \pm 0.014$ & $0.885 \pm 0.026$ & $0.890 \pm 0.034$ & $0.895 \pm 0.016$ \\
Liver & $3.055 \pm 0.052$ & $3.093 \pm 0.071$ & $3.124 \pm 0.094$ & $3.113 \pm 0.081$ \\
Spleen & $0.293 \pm 0.021$ & $0.286 \pm 0.032$ & $0.298 \pm 0.044$ & $0.296 \pm 0.012$ \\
Lung & $0.850 \pm 0.029$ & $0.837 \pm 0.044$ & $0.851 \pm 0.036$ & $0.841 \pm 0.024$ \\
Kidney & $0.503 \pm 0.034$ & $0.515 \pm 0.019$ & $0.512 \pm 0.014$ & $0.505 \pm 0.022$ \\
\hline
\end{tabular}

for $0.02,0.05,0.50$, and $5.00 \mu \mathrm{g} / \mathrm{mL}$ were $<4.54 \%$, and the inter-assay coefficients of variation for $0.02,0.05,0.50$, and $5.00 \mu \mathrm{g} / \mathrm{ml}$ were $3.29,2.07$, and $1.33 \%$, respectively. The typical regression equation was $y=40.737 x-2.2772, R^{2}=0.996$. The chromatogram is shown in Figures 4A-C; the blank is shown in Figure 4A, the lower limit of quantification (LLOQ) is shown in Figure 4B, and the measured plasma samples $16 \mathrm{~h}$ after oral and i.v. administration are shown in Figures 4C,D.

\section{Pharmacokinetics Analysis}

The theoretical compartmental theoretical concentration-time profiles by non-linear regression equation analysis of $\mathrm{MBF}$ concentration-time profiles after oral Petsen, Marbocyl and i.v. MBF administrations are presented in Figure 5. After orally administrated Petsen, the theoretical compartmental theoretical concentration-time profiles of plasma were analyzed in accordance with an absorbing two-compartment open model; after i.v. administrated MBF, the concentration-time profile of plasma was analyzed in accordance with the non-compartment analysis. The main PK parameters of these two administration methods are shown in Table 4; these parameters were determined with WinNonlin software. The main parameters $t_{1 / 2}$ or $t_{1 / 2 \beta}, \mathrm{Cl}_{\mathrm{b}}$, $\mathrm{AUC}_{0-\infty}, C_{\max }$, and $K_{e}$ were $13.78 \mathrm{~h}, 0.14 \mathrm{~L} / \mathrm{h}, 13.69 \mu \mathrm{g} . \mathrm{h} / \mathrm{ml}$, unavailable value and $0.053 \mathrm{~h}^{-1}$ after intravenous administrated MBF, 22.14 h, 0.15 L/h, $13.27 \mu \mathrm{g} . \mathrm{h} / \mathrm{ml}, 0.95 \mu \mathrm{g} / \mathrm{ml}$, and $0.09 \mathrm{~h}^{-1}$ after orally administrated Petsen, and $16.47 \mathrm{~h}, 0.14 \mathrm{~L} / \mathrm{h}, 14.10$ $\mu \mathrm{g} . \mathrm{h} / \mathrm{ml}, 0.97 \mu \mathrm{g} / \mathrm{ml}$, and $0.11 \mathrm{~h}^{-1}$ after orally administrated Marbocyl. Moreover, the bioavailability values of Petsen and Marbocyl after oral administration were 97.11 and $101.70 \%$, respectively.

\section{Bioequivalence Analysis}

The mean $\pm \mathrm{SD}$ of $\mathrm{MBF}$ concentrations-time profiles are presented in Figure 5 after oral two formulations, and the main descriptive PK parameters, are reported in Table 5.

\section{Bioequivalence Analysis}

Log-transformed $C_{\max }, \mathrm{AUC}_{0-\infty}$, and untransformed $T_{\max }$ of the test formulation (Petsen) were compared with the reference one (Marbocyl) for a bioavailability study with ANOVA analysis and $90 \%$ CI. It showed a significant difference in that $T_{\max }$ of Petsen $(1.46 \mathrm{~h})$ was longer than Marbocyl $(1.10 \mathrm{~h})$ in Table 5. This point might indicate the bioequivalence between Petsen and Marbocyl was not the same. This might be caused by a small magnitude and biological difference. However, no statistically significative differences were observed for $C_{\max }$ or $\mathrm{AUC}_{0-\infty}$ in Table 5. The relative bioavailability of the test product compared to the reference one was $94.11 \pm 10.28 \%$ (Table 5).

The two one-sided $T$ tests estimated the ratios mean of log-transformed $C_{\max }, \mathrm{AUC}_{0-\infty}$, and $90 \% \mathrm{CI}$ on the test to reference formulations. Obtained values were 99.3, 99.2, and $91.9-107.2 \%, 92.0-102.1 \%$, all in the range of $80-125 \%$ within the bioequivalence acceptance range (Table 6). These results demonstrated that Petsen was bioequivalent to the reference product (Marbocyl) in dogs.

\section{DISCUSSION}

Compared with the previously published reports and the PK profiles of Marbocyl, Petsen has also several advantages, including long-action, sustained release, and convenient administration to pets (Yang and Hu, 2006; Ghimire et al., 2007; Walther et al., 2014). In the present study, we performed a comprehensive toxicological evaluation of Petsen by conducting animal safety studies in beagle dogs. At the doses tested, Petsen was shown to be safe. In addition, this study also revealed the antibacterial activity of $\mathrm{MBF}$ from Petsen against four kinds of common pathogenic bacteria in vitro, as well as pharmacokinetic characteristics of MBF after administration of Petsen tablets in vivo.

In the safety study, no Petsen-related effects were observed in beagle dogs administered Petsen, in terms of mortality, morbidity, organ weight, body weight, total autopsy results, or microscopic manifestations in organ and histopathological examination. There were minimal differences in weight gain and food consumption among the control, low and middle dose groups, but an effect was seen at the highest dose used, as shown in Figure 2 and Supplemental Table 1. Moreover, there were also no treatment-related lesions based on the histopathology and examination of organs, as seen in Figure 3. It is known that administration of fluoroquinolones in animals and humans can cause toxicity such as gastrointestinal disturbances, anaphylaxis, hepatic and renal function injury, and in particular, articular cartilage lesions (Ball, 2000; Robinson et al., 2005; Thompson, 2007). Our study found no lesions in the articular cartilage among the three Petsen treatment groups (Supplemental Table 2). PLT was decreased and WBC was increased in the 6 and 10 $\mathrm{mg} / \mathrm{kg}$ treatment groups on day 14 and 40 (Table 1). Further TBL, ALT, and AST were slightly decreased while ALP and BUN were slightly increased in the 6 and $10 \mathrm{mg} / \mathrm{kg}$ treatment groups, compared with the control group (Table 2). Moreover, there seemed to be a fall in $\mathrm{Na}$ across all groups at day 14th day compared to the control group. Although these indices presented significant differences in the test group compared to the control group on the 14 and 40th day $(P<0.05)$, these were not biologically significant changes; these values did not fall outside the reference ranges. Therefore, the $10 \mathrm{mg} / \mathrm{kg}$ b.w. the dose was regarded as the no observed adverse effect level (NOAEL) of Petsen in the current study. In a previous 13 -week repeatdose study, beagle dogs were given daily oral doses of 1,4 , and $40 \mathrm{mg} / \mathrm{kg}$ b.w. MBF in gelatin capsules. The typical quinoloneinduced changes were observed at $40 \mathrm{mg} / \mathrm{kg}$ b.w. in the articular 
A

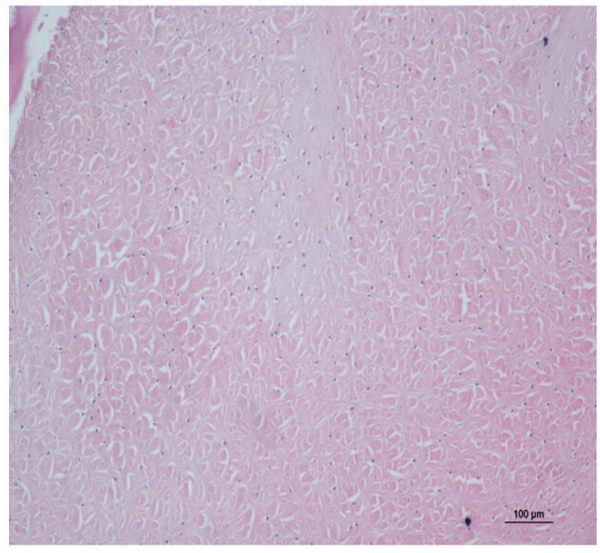

B

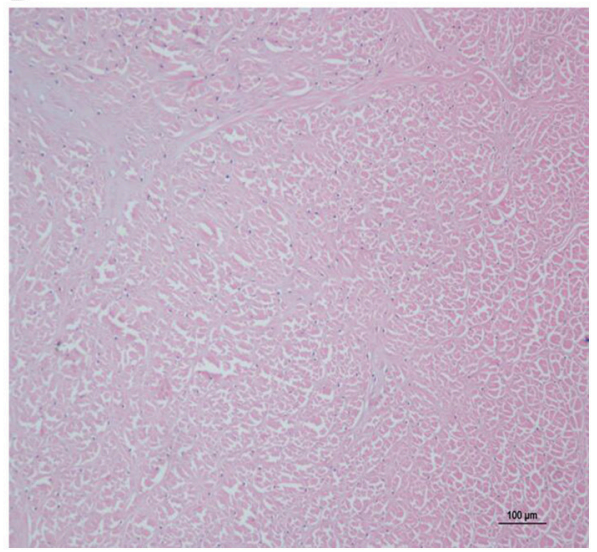

FIGURE 3 | Microphotographs of articular cartilage in control and high dose treatment groups (10 mg/kg). (A) Represented control group, (B) represented high dose treatment group $(10 \mathrm{mg} / \mathrm{kg})$.
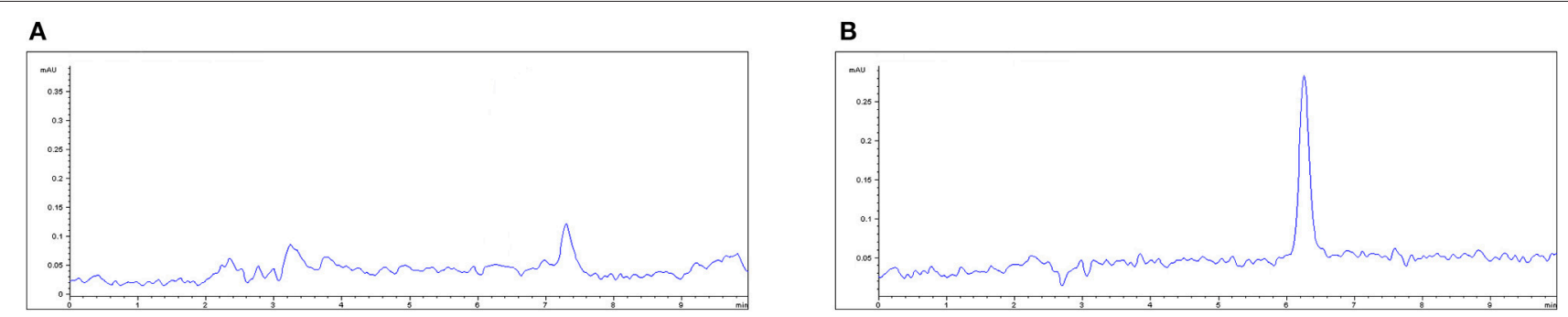

C

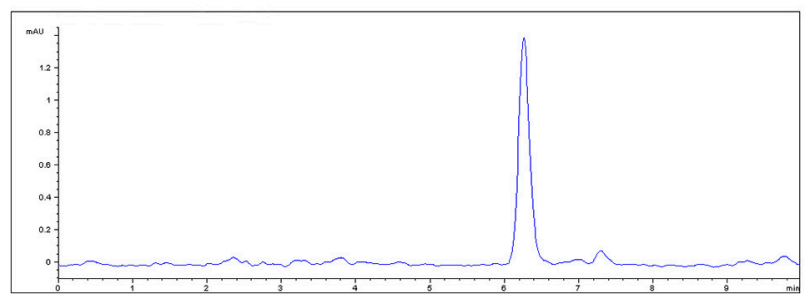

D

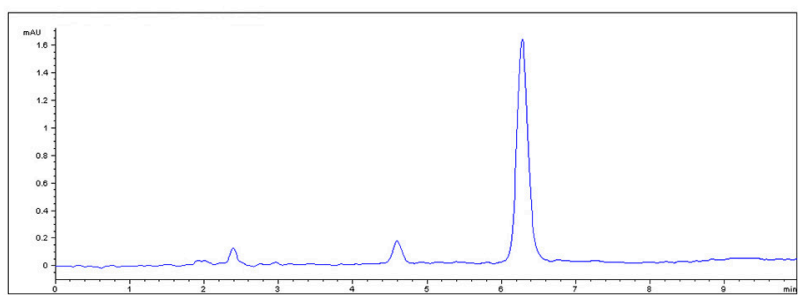

FIGURE 4 | The HPLC method for MBF quantification in plasma. (A) Blank plasma sample, (B) plasma sample at the LLOQ of $0.05 \mu \mathrm{g} / \mathrm{ml}$, (C) plasma sample after oral administration of Petsen at the point of $16 \mathrm{~h}$, (D) plasma sample after i.v. administration of MBF at the point of $16 \mathrm{~h}$. MBF at the peak time of $6.3 \mathrm{~min}$.

cartilage, and other toxic symptoms such as testicular tubular atrophy and spermatic granuloma also occurred in one dog at this dose. The recommended NOAEL was $4 \mathrm{mg} / \mathrm{kg}$ b.w. (Committee for Veterinary Medicinal Products, 2009a). Another study reported that no substance-related effects were found in immature dogs after being given doses of up to $6 \mathrm{mg} / \mathrm{kg} \mathrm{b}$.w. for 13 weeks, and the recommended NOAEL of MBF was $6 \mathrm{mg} / \mathrm{kg}$ b.w. (Committee for Veterinary Medicinal Products, 2009b). Moreover, in a two-generation study of rats fed diets containing 10,70 , and $500 \mathrm{mg} / \mathrm{kg}$ b.w., overt signs of toxicity such as impaired male fertility, reductions in implantation rate, litter size, and pup weight, as well as increased pup mortality were observed at doses of 10 and $500 \mathrm{mg} / \mathrm{kg}$ b.w. Therefore, the recommended NOAEL in rats was $10 \mathrm{mg} / \mathrm{kg}$ b.w. (Committee for Veterinary
Medicinal Products, 2009b). In the present study, no significant toxicological effects were found up to $10 \mathrm{mg} / \mathrm{kg}$ in beagle dogs, and the NOAEL of Petsen was suggested to be $10 \mathrm{mg} / \mathrm{kg}$. This Petsen dose is higher than the previously described report (4 $\mathrm{mg} / \mathrm{kg}$ b.w.) in beagle dogs, but equal to the dose in rats. The difference for this might arises because of the decision to have dose of 4 and $40 \mathrm{mg} / \mathrm{kg}$ in the former study. This study provided a higher dose of NOAEL of MBF, which could be regarded as a reference in the future study.

Four kinds of bacteria with 50 strains were selected for MIC determination of Petsen. The $\mathrm{MIC}_{90}$ of these four kinds of bacteria (S. aureus, E. coli, P. multocida, Streptococcus) was $2.00,4.00,0.25$, and $0.50 \mu \mathrm{g} / \mathrm{ml}$, respectively (Figure 1). All of the $\mathrm{MIC}_{90}$ values were lower than $4 \mu \mathrm{g} / \mathrm{ml}$, and the $\mathrm{MIC}_{90}$ of 


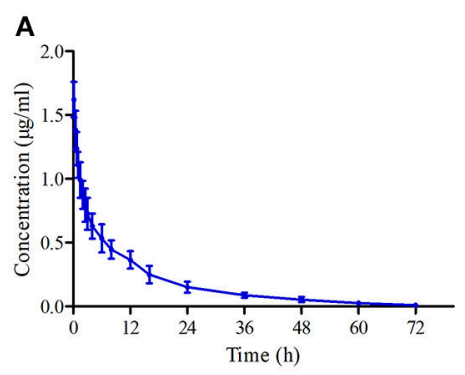

C

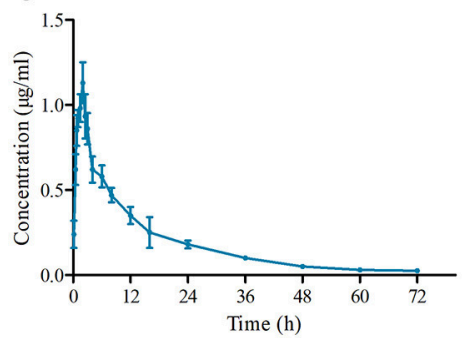

I.VMBF

B

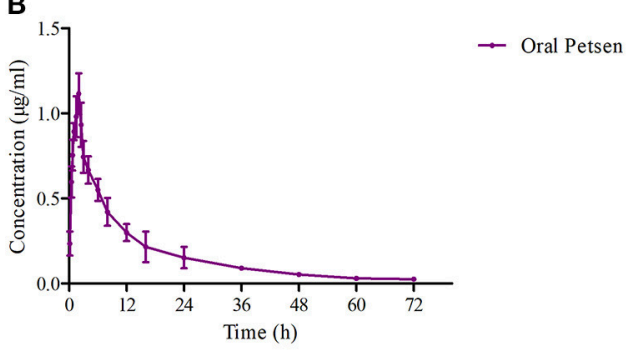

$\rightarrow$ Oral Marbocyl

FIGURE 5 | The curves of MBF concentration-time in plasma at a dose of $2 \mathrm{mg} / \mathrm{kg}$ after i.v. administrated (A) MBF, (B) oral Petsen, and (C) Marbocyl, respectively. $\mathrm{MBF}$ in plasma was determined at $0.17,0.5,0.75,1,2,2.5,3,4,6,8,12,16,24,36,48,60$, and $72 \mathrm{~h}$.

TABLE 4 | Main PK parameters after oral and i.v. administration in beagle dogs $(n=12)$.

\begin{tabular}{lccc}
\hline \multirow{2}{*}{ Parameters } & \multicolumn{3}{c}{ Mean \pm SD $(\boldsymbol{n}=\mathbf{1 2})$} \\
\cline { 2 - 4 } & MBF (i.v) & Petsen (orally) & Marbocyl (orally) \\
\hline$K_{e}\left(\mathrm{~h}^{-1}\right)$ & $0.053 \pm 0.004$ & $0.09 \pm 0.01$ & $0.11 \pm 0.05$ \\
$t_{1 / 2}(\mathrm{~h})$ & $13.78 \pm 1.21$ & - & - \\
$t_{1 / 2 \beta}(\mathrm{h})$ & - & $22.14 \pm 2.41$ & $16.47 \pm 2.18$ \\
$\mathrm{Cl}_{\mathrm{b}}(\mathrm{L} / \mathrm{h})$ & $0.14 \pm 0.08$ & $0.15 \pm 0.09$ & $0.14 \pm 0.04$ \\
$\mathrm{MRT}_{(\mathrm{h})}$ & $13.70 \pm 1.48$ & $21.73 \pm 1.88$ & $21.41 \pm 3.36$ \\
$\mathrm{AUC} \mathrm{C}_{0-\infty}(\mu \mathrm{g} . \mathrm{h} / \mathrm{ml})$ & $13.69 \pm 1.31$ & $13.27 \pm 1.48$ & $14.10 \pm 2.18$ \\
$T_{\max }(\mathrm{h})$ & - & $1.46 \pm 0.12$ & $1.10 \pm 0.38$ \\
$C_{\max }(\mu \mathrm{g} / \mathrm{ml})$ & - & $0.95 \pm 0.14$ & $0.97 \pm 0.18$ \\
$F(\%)$ & - & $97.11 \pm 4.87$ & $101.70 \% \pm 5.12$ \\
\hline
\end{tabular}

$K_{e}$, elimination rate constant; $t_{1 / 2}$ and $t_{1 / 2 \beta}$, half-life of elimination under noncompartmental and compartmental models; $\mathrm{Cl}_{\mathrm{b}}$, total body clearance; MRT, mean residence time; $A \cup C_{0-\infty}$, area under curve from 0 to $\infty ; T_{\max }$, time to the concentration peak; $C_{\max }$, the concentration in the peak; $F$, bioavailability.

P. multocida and Streptococcus was lower than 1. Streptococcus was the most susceptible to Petsen. It had been reported that the MICs of MBF against the isolates of E. coli, Streptococcus, and $S$. aureus, isolated from pigs in China, were in the range of $0.13-0.25 \mu \mathrm{g} / \mathrm{ml}$; other studies have also reported E. coli strains resistant to MBF whose MICs ranged from 8 to $32 \mu \mathrm{g} / \mathrm{ml}$ (Pellet et al., 2006; Ding et al., 2010; Andraud et al., 2011; Ferran et al., 2013). Our findings are similar to these previous reports, suggesting that these four kinds of bacteria are sensitive to Petsen, according to the CLSI M100-S23 guide document. MICs of three $E$. coli were up to 8 and $16 \mu \mathrm{g} / \mathrm{ml}$. For the susceptibility breakpoint evaluation of $E$. coli to MBF, a previous study had
TABLE 5 | Pharmacokinetic parameters for the Test Formulation (Petsen) and Reference Formulation (Marbocyl), $p$-value, and relative fraction.

\begin{tabular}{llrrrr}
\hline Parameters & Unit & \multicolumn{1}{c}{ Petsen } & Marbocyl & ANOVA & $\boldsymbol{F}(\%)$ \\
\hline $\mathrm{AUC}_{0-\infty}$ & $\mu \mathrm{g} \cdot \mathrm{h} / \mathrm{mL}$ & $13.27 \pm 1.48$ & $14.10 \pm 2.18$ & 0.313 & $94.11 \pm 10.28$ \\
$C_{\max }$ & $\mu \mathrm{g} / \mathrm{mL}$ & $0.95 \pm 0.14$ & $0.97 \pm 0.18$ & 0.874 & \\
$T_{\max }$ & $\mathrm{H}$ & $1.46 \pm 0.12$ & $1.10 \pm 0.38$ & $>0.05^{\star}$ & \\
\hline
\end{tabular}

F, represent relative bioavailability.

*Wilcoxon test.

suggested that MIC $>8 \mu \mathrm{g} / \mathrm{ml}$ was categorized as resistant (Andraud et al., 2011). However, based on the calculated $\mathrm{MIC}_{90}$ of E. coli to MBF ( $4 \mu \mathrm{g} / \mathrm{ml})$, the MBF concentrations were focused on the intestinal tract, the site of infection with $E$. coli, and the $C_{\max }$ was $11.28 \mu \mathrm{g} / \mathrm{ml}$ in intestinal tract which was much higher than the $\mathrm{MIC}_{90}$ in the previously published report by Lei et al. (2017a). Therefore, our results suggest that Petsen will result in concentrations of MBF active against E. coli.

Following i.v. injection, the elimination half-life $\left(t_{1 / 2}\right)$ of $\mathrm{MBF}$ (13.78 h; as shown in Table 4) was much longer in beagle dogs than in broilers $(5.26 \mathrm{~h})$ and buzzards $(4.11 \mathrm{~h})$ (Garcia-Montijano et al., 2001; García-Montijano et al., 2003; Anadón et al., 2002; Haritova et al., 2006). Moreover, the value of $t_{1 / 2}$ after i.v. administration of MBF was similar $(13.78 \mathrm{~h}$ ) to a previous report (Yohannes et al., 2015). However, after oral administration of Petsen at a dose of $2 \mathrm{mg} / \mathrm{kg}$, the $t_{1 / 2 \beta}(22.14 \mathrm{~h})$ value was higher than that in beagles $(7.51 \mathrm{~h})$ after intramuscular injection (i.m.) of MBF in the study by Yohannes (Yohannes et al., 2015), and also higher than that after i.v. administration in the current study. This difference was probably related to the continued absorption of MBF from the oral administration site in the period of the 
TABLE 6 | Two-one sided $T$-test and 90\% confidence interval.

\begin{tabular}{lrrrcc}
\hline Parameters & Petsen & Marbocyl & $\mathbf{9 0 \%}$ Cl & $\begin{array}{c}\text { Ratio } \\
\text { (T/R) (\%) }\end{array}$ & $\begin{array}{c}\text { Acceptable } \\
\text { range (\%) }\end{array}$ \\
\hline $\mathrm{AUC}_{0-\infty}$ & $13.27 \pm 1.48$ & $14.10 \pm 2.18$ & $92.0-102.1$ & 99.2 & $80-125$ \\
$C_{\max }$ & $0.95 \pm 0.14$ & $0.97 \pm 0.18$ & $91.9-107.2$ & 99.3 & $80-125$ \\
\hline
\end{tabular}

${ }^{*}$ Present significant difference $P<0.05$.

elimination phase, thereby prolonging the elimination phase time of MBF. Petsen showed high bioavailability, close to $100 \%$ (97.11\%), after oral administration in beagle dogs (see Table 4). As the bactericidal activity of MBF was concentration-dependent, the high absorption and bioavailability could contribute to the bactericidal activity of MBF in vivo. The bioavailability of Petsen in beagle dogs in this study was comparable with other species, such as sheep, goats, and pigs, and was similar to that previously reported in beagle dogs; the bioavailability in all these animals has been shown to be close to 100\% (Schneider et al., 1996; Waxman et al., 2001; Ding et al., 2010; Sidhu et al., 2010a,b; Marín et al., 2013). The high bioavailability may contribute to the prolonged elimination half-life after oral or i.m. administration; this may have induced a higher AUC. The $C_{\max }(1.10 \mu \mathrm{g} / \mathrm{ml})$ of Petsen achieved in this study (Table 4) was higher than the $\mathrm{MIC}_{90}$ of P. multocida and Streptococcus, and was also higher than other breakpoints of fluoroquinolones recommended against susceptible bacteria, based on the CLSI M100-S19 guide document. The $C_{\max }(1.10 \mu \mathrm{g} / \mathrm{ml})$ in this study was similar to that in pigs $(1.03 \mu \mathrm{g} / \mathrm{ml}$ ) (Ding et al., 2010; Marín et al., 2013). $C_{\max }$ obtained from orally administered MBF $(1.10 \mu \mathrm{g} / \mathrm{ml})$ was lower than that obtained from i.m. administration in pigs $(1.81 \mu \mathrm{g} / \mathrm{ml}$ ), as reported by Ding (Ding et al., 2010). Further, $C_{\max }$ in this study was lower than that reported by Yohannes $(1.76 \mu \mathrm{g} / \mathrm{ml})$ (Table 4$)$.

For the bioequivalence trial of these two MBT preparations, and to perform a statistical comparison, $\mathrm{AUC}_{0-\infty}, C_{\max }$, and $T_{\max }$ were chosen. When there are no statistically significant differences in these indices, bioequivalence is considered to have been shown (Vătăş̧escu et al., 2011; Marchidanu et al., 2013). In our findings, the three indices in Table 5 were revealed were non-significant between test (Petsen) and reference formulations (Marbocyl) $(p<0.05)$. The $\mathrm{AUC}_{0-144 \mathrm{~h}}$ and $\mathrm{AUC}_{0-\infty}, C_{\max }$ outcomes showing $90 \%$ of CI were inside the CIs (80-125\%) set

\section{REFERENCES}

Albarellos, G. A., Montoya, L., and Landoni, M. F. (2005). Pharmacokinetics of marbofloxacin after single intravenous and repeat oral administration to cats. Vet. J. 170, 222-229. doi: 10.1016/j.tvjl.2004.05.011

Alp, H. (2009). The Evaluation and Importance of Bioequivalence in Veterinary Medicine. Atatürk Üniversitesi Veteriner Bilimleri Dergisi, Diyarbakir.

Anadón, A., Martínez-Larra-aga, M. R., Díaz, M. J., Martínez, M. A., Frejo, M. T., Martínez, M., et al. (2002). Pharmacokinetic characteristics and tissue residues for marbofloxacin and its metabolite N-desmethyl-marbofloxacin in broiler chickens. Am. J. Vet. Res. 63, 927-933. doi: 10.2460/ajvr.2002.63.927

Andraud, M., Chauvin, C., Sanders, P., and Laurentie, M. (2011). Pharmacodynamic modeling of in vitro activity of marbofloxacin against by the all guidelines. Therefore, these findings proved that the MBT-test product (Petsen) was bioequivalent to the reference one (Marbocyl).

As a tablet, oral administration of Petsen is recommended for pets. Thus, these results reveal that Petsen has high plasma concentration, wide distribution, and high bioavailability in beagle dogs, which supports its use as an alternative to Marbocyl.

\section{CONCLUSION}

The results of this study revealed that, as a new formulation, Petsen has low toxicity in target animals (beagle dogs), antibacterial activity in vitro, and a pharmacokinetic profile in terms of high plasma concentration, wide distribution, long action, and bioequivalent which was similar to the reference one (Marbocyl). This study also provided a reasonable theoretical foundation for veterinary clinical application. Petsen might be conveniently and widely used for pets in veterinary clinic practice.

\section{AUTHOR CONTRIBUTIONS}

JC: Conceived the study; QL and ZL: Designed the experiments. $\mathrm{ZL}, \mathrm{BF}$, and BY: Performed the experiments; ZL: Wrote the manuscript; QH, SA, HK, and JC: Improved the language. All authors reviewed the manuscript.

\section{FUNDING}

This work was partly supported by the China Agricultural Research System (CARS-36).

\section{ACKNOWLEDGMENTS}

We thank Huazhong Agricultural University for permission to conduct this research.

\section{SUPPLEMENTARY MATERIAL}

The Supplementary Material for this article can be found online at: https://www.frontiersin.org/articles/10.3389/fphar. 2018.00306/full\#supplementary-material

Escherichia coli strains. Antimicrob. Agents Chemother. 55, 756-761. doi: 10.1128/AAC.00865-10

Ball, P. (2000). "Fluoroquinolone safety and tolerability," in First International Moxifloxacin Symposium, ed L. Mandell (Berlin; Heidelberg: Springer) 138-143.

Bousquetmelou, A., Cester, C. C., Serthelon, J. P., and Gruet, P. (1997). Pharmacodynamic Study of the Potential Epileptic Effect of Combination Therapy with Marbofloxacin-tolfenamic Acid in the Dog. Food and Agriculture Organization of the United Nation; FAO of the UN, Toulouse.

Carlotti, D. N., Guaguere, E., Koch, H. J., Guiral, V., and Thomas, E. (1998). Marbofloxacin for the Systemic Treatment of Pseudomonas spp. Suppurative Otitis Externa in the Dog. Food and Agriculture Organization of the United Nations; FAO of the UN, Carbon-Blanc. 
Carlotti, D. N., Guaguere, E., Pin, D., Jasmin, P., Thomas, E., and Guiral, V. (1999). Therapy of difficult cases of canine pyoderma with marbofloxacin: a report of 39 dogs. J. Small Anim. Pract. 40, 265-270. doi: 10.1111/j.1748-5827.1999.tb03077.x

Chen, M. L., Shah, V., Patnaik, R., Adams, W., Hussain, A., Conner, D., et al. (2001). Bioavailability and bioequivalence: an FDA regulatory overview. Pharm. Res. 18, 1645-1650. doi: 10.1023/A:1013319408893

Committee for Veterinary Medicinal Products (2009a). Committee for Veterinary Medicinal Products Marbofloxacin Summary Report (1). Available online at: http://www.ema.europa.eu/docs/en_GB/document_library/Maximum Residue_Limits_-_Report/2009/11/WC500014864.pdf

Committee for Veterinary Medicinal Products (2009b). Committee For Veterinary Medicinal Products Marbofloxacin Summary Report (2). http://www.ema. europa.eu/docs/en_GB/document_library/Maximum_Residue_Limits_-_ Report/2009/11/WC500014865.pdf

Cotard, J. P., Gruet, P., Pechereaut, D., Moreaus, P., Pages, J. P., and, Thomas, E., et al. (1995). Comparative studv of marbofloxacin and amoxicillin-clavulanic acid in the treatment of urinarv tract infection; in dogs. J. Small Anim. Pract. 36, 349-353. doi: 10.1111/j.1748-5827.1995.tb02948.x

Davit, B. M., Kanfer, I., Yu, C. T., and Cardot, J. M. (2016). BCS biowaivers: similarities and differences among, EMA, FDA, and WHO requirements. AAPS J. 18, 612-618. doi: 10.1208/s12248-016-9877-2

Ding, H., Li, Y., Chen, Z., Rizwan-Ul-Haq, M., and Zeng, Z. (2010). Plasma and tissue cage fluid pharmacokinetics of marbofloxacin after intravenous, intramuscular, and oral single-dose application in pigs. J. Vet. Pharmacol. Therapeut. 33, 507-510. doi: 10.1111/j.1365-2885.2010.01164.x

Ferran, A. A., Bibbal, D., Pellet, T., Laurentie, M., Gicquel-Bruneau, M., Sanders, P., et al. (2013). Pharmacokinetic/pharmacodynamic assessment of the effects of parenteral administration of a fluoroquinolone on the intestinal microbiota: comparison of bactericidal activity at the gut versus the systemic level in a pig model. Int. J. Antimicrob. Agents. 42, 429-435. doi: 10.1016/j.ijantimicag.2013.07.008

Frazier, D. L., Thompson, L., Trettien, A., and Evans, E. I. (2000). Comparison of fluoroquinolone pharmacokinetic parameters after treatment with marbofloxacin, enrofloxacin, and difloxacin in dogs. J. Vet. Pharmacol. Therapeut. 23, 293-302. doi: 10.1046/j.1365-2885.2000.00285.x

Galgatte, U. (2014). Study on requirements of bioequivalence for registration of pharmaceutical products in India, South Africa and Australia. Saudi Pharmaceut. J. 22, 391-402. doi: 10.1016/j.jsps.2013.05.001

García-Montijano, M., González, F., Waxman, S., Sánchez, C., Lucas, J. J. D., Andrés, M. S., et al. (2003). Pharmacokinetics of marbofloxacin after oral administration to Eurasian buzzards (Buteo buteo). J. Avian Med. Surg. 17, 185-190. doi: 10.1647/2001-033

Garcia-Montijano, M., Waxman, S., Sánchez, C., Quetglas, J., San Andrés, M. I., González, F., et al. (2001). The disposition of marbofloxacin in Eurasian buzzards (Buteo buteo) after intravenous administration. J. Vet. Pharmacol. Therapeut. 24, 155-157. doi: 10.1046/j.1365-2885.2001.00327.x

Gherghiceanu, F., Sandulovici, R., Prasacu, I., Anuta, V., and Mircioiu, C. (2016). Bioequivalence implies therapeutic equivalence. I. biostatistical approach. Farmacia 64, 823-827.

Ghimire, M., Mcinnes, F. J., Watson, D. G., Mullen, A. B., and Stevens, H. N. (2007). In-vitro/in-vivo correlation of pulsatile drug release from press-coated tablet formulations: a pharmacoscintigraphic study in the beagle dog. Eur. J. Pharmaceut. Biopharmaceut. 67, 515-523. doi: 10.1016/j.ejpb.2007.03.002

Good Laboratory Practice Regulations of China (2012). Technical Guidelines of Veterinary Drug Research and Good Laboratory Practice Regulations of China. ISBN:978-7-122-13394-6.

Government of Canada HC, Health Products, and Food Branch VDD. (2014). Government of Canada HC, Health Products, and Food Branch VDD. VICH Guideline 52: Bioequivalence - Blood Level Bioequivalence Study (Step 4) - 2014 Health Canada Consultation Notice, Ottawa, ON.

Haritova, A. M., Rusenova, N. V., Parvanov, P. R., Lashev, L. D., and FinkGremmels, J. (2006). Integration of pharmacokinetic and pharmacodynamic indices of marbofloxacin in turkeys. Antimicrob. Agents Chemother. 50, 3779-3785. doi: 10.1128/AAC.00711-05

Kaushal, N., Singh, S. K., Gulati, M., Vaidya, Y., and Kaushik, M. (2016). Study of regulatory requirements for the conduct of bioequivalence studies in US, Europe, Canada, India, ASEAN and SADC countries: impact on generic drug substitution. J. Appl. Pharmaceut. Sci. 6, 206-222. doi: 10.7324/JAPS.2016.60430

Kux, L. (2011). Guidance for Industry on Target Animal Safety and Effectiveness Protocol Development and Submission; Availability. Federal Register.

Lei, Z., Cao, J., and He, Q. (2017a). Pharmacokinetic and Pharmacodynamic Evaluation of Marbofloxacin and PK/PD Modelling against E scherichia coli in Pigs. Front. Pharmacol. 8:542. doi: 10.3389/fphar.2017.00542

Lei, Z., Liu, Q., Yang, B., Ahmed, S., Xiong, J., Song, T., et al. (2017b). Evaluation of bioequivalence of two long-acting $20 \%$ oxytetracycline formulations in pigs. Frontiers Vet. Sci. 4:61. doi: 10.3389/fvets.2017.00061

Lei, Z., Liu, Q., Yang, B., Xiong, J., Li, K., Ahmed, S., et al. (2017c). Clinical efficacy and residue depletion of $10 \%$ enrofloxacin enteric-coated granules in pigs. Front. Pharmacol. 8:294 doi: 10.3389/fphar.2017.00294

Listed, N. (1998). Bioavailability and bioequivalence requirements; abbreviated applications; proposed revisions-FDA. Proposed rule. Federal Register. 63, 64222-64228.

Marchidanu, D., Raducanu, N., Miron, D. S., Radulescu, F. S. R., Anuta, V., Mircioiu, I., et al. (2013). Comparative pharmacokinetics of rifampicin and 25desacetyl rifampicin in healthy volunteers after single oral dose administration. 61, 398-410.

Marín, P., Alamo, L. F., Escudero, E., Fernándezvarón, E., Hernandis, V., and Cárceles, C. M. (2013). Pharmacokinetics of marbofloxacin in rabbit after intravenous, intramuscular, and subcutaneous administration. Res. Vet. Sci. 94, 698-700. doi: 10.1016/j.rvsc.2013.01.013

Ozdemir, N., and Yildirim, M. (2006). Bioequivalence study of two longacting oxytetracycline formulations in sheep. Vet. Res. Commun. 30:929. doi: 10.1007/s11259-006-3235-2

Paradis, M., Abbey, L., Baker, B., Coyne, M., Hannigan, M., Joffe, D., et al. (2001). Evaluation of the clinical efficacy of marbofloxacin (Zeniquin) tablets for the treatment of canine pyoderma: an open clinical trial. Vet. Dermatol. 12, 163-169. doi: 10.1046/j.1365-3164.2001.00195.x

Pellet, T., Gicquel-Bruneau, M., Sanders, P., and Laurentie, M. (2006). Comparison of faecal and optimal growth conditions on in vitro pharmacodynamic activity of marbofloxacin against Escherichia coli. Res. Vet. Sci. 80, 324-335. doi: 10.1016/j.rvsc.2005.07.001

Pfaller, M. A., Andes, D., Diekema, D. J., Espinel-Ingroff, A., Sheehan, D., and Testing CSfAS. (2010). Wild-type MIC distributions, epidemiological cutoff values and species-specific clinical breakpoints for fluconazole and Candida: time for harmonization of CLSI and EUCAST broth microdilution methods. Drug Resist. Updat. 13, 180-195. doi: 10.1016/j.drup.2010.09.002

Robinson, A. A., Belden, J. B., and Lydy, M. J. (2005). Toxicity of fluoroquinolone antibiotics to aquatic organisms. Environ. Toxicol. Chem. 24, 423-430. doi: 10.1897/04-210R.1

Rockville, M. (2000). FDA Guidance for Industry a) Bioavailability and Bioequivalence Studies for Orally Administered Drug Products-General Considerations. Food and Drug Administration, Washington, DC.

Sandulovici, R., Prasacu, I., Mircioiu, C., Voicu, V., Medvedovici, A., and Anuta, V. (2009). Mathematical and phenomenological criteria in selection of pharmacokinetic model for M1 metabolite of pentoxyphylline. Farmacia 57, 235-246. Available online at: https://pdfs.semanticscholar.org/c122/ 0703a36f87c548062f86cla8bb18ff707ee2.pdf

Schneider, M., Thomas, V., Boisrame, B., and Deleforge, J. (1996). Pharmacokinetics of marbofloxacin in dogs after oral and parenteral administration. J. Veterin. Pharmacol. Therapeut. 19, 56-61. doi: 10.1111/j.1365-2885.1996.tb00009.x

Schneider, M., Vallé, M., Woehrlé, F., and Boisramé, B. (2004). Pharmacokinetics of marbofloxacin in lactating cows after repeated intramuscular administrations and pharmacodynamics against mastitis isolated strains. J. Dairy Sci. 87, 202-211. doi: 10.3168/jds.S0022-0302(04)73159-8

Shan, Q., Wang, J., Yang, F., Ding, H., Liang, C., Lv, Z., et al. (2014). Pharmacokinetic/pharmacodynamic relationship of marbofloxacin against Pasteurella multocida in a tissue-cage model in yellow cattle. J. Veter. Pharmacol. Therapeut. 37, 222-230. doi: 10.1111/jvp.12078

Shuren, J. (2012). Guidance for Industry on Development of Target Animal Safety and Effectiveness Data to Support Approval of Non-Steroidal Anti-Inflammatory Drugs for Use in Animals Availability, Rockville.

Sidhu, P. K., Landoni, M. F., Aliabadi, F. S., and Lees, P. (2010a). Pharmacokinetic and pharmacodynamic modelling of marbofloxacin administered alone 
and in combination with tolfenamic acid in goats. Vet. J. 184, 219-229. doi: 10.1016/j.tvjl.2009.02.009

Sidhu, P. K., Landoni, M. F., Aliabadi, F. S., and Lees, P. (2010b). PK-PD integration and modeling of marbofloxacin in sheep. Res. Vet. Sci. 88, 134-141. doi: 10.1016/j.rvsc.2009.05.013

Sidhu, P. K., Landoni, M. F., Aliabadi, M. H., Toutain, P. L., and Lees, P. (2011). Pharmacokinetic and pharmacodynamic modelling of marbofloxacin administered alone and in combination with tolfenamic acid in calves. J. Veter. Pharmacol. Therapeut. 34, 376-387. doi: 10.1111/j.1365-2885.2010.01247.x

Soussy, C. J., Leclercq, R., Deforges, L., and Duval, J. (1989). In vitro antibacterial activity of a new fluoroquinolone, fleroxacin as a function of the sensitivity or resistance to nalidixic acid and to pefloxacin. Pathol. Biol. 37, 364-369.

Spreng, M., Deleforge, J., Thomas, V., Boisramé, B., and Drugeon, H. (1995). Antibacterial activity of marbofloxacin. A new fluoroquinolone for veterinary use against canine and feline isolates. J. Veterin. Pharmacol. Therapeut. 18, 284-289. doi: 10.1111/j.1365-2885.1995.tb00592.X

Sun, J., Xiao, X., Huang, R. J., Yang, T., Chen, Y., Fang, X. et al. (2015). In vitro dynamic pharmacokinetic/pharamco-dynamic (PK/PD) study and COPD of Marbofloxacin against Haemophilus parasuis. BMC Vet. Res. 11:293. doi: 10.1186/s12917-015-0604-5

Thomas, V. M., Guillardeau, L. D., Thomas, E. R., and Boisramé, B. (1997). Update on the sensitivity of recent European canine and feline pathogens to marbofloxacin. Veterin. Quart. 19(Suppl. 1), 52-53. doi: 10.1080/01652176.1997.9694812

Thompson, A. M. (2007). Ocular toxicity of fluoroquinolones. Clin. Exp. Ophthalmol. 35, 566-577. doi: 10.1111/j.1442-9071.2007.01552.x

Tohamy, M. A., and El-Gendy, A. A. M. (2013). Some pharmacokinetic aspects and bioavailability of marbofloxacin in foals. J. Basic Appl. Sci. 2, 46-50. doi: 10.1016/j.bjbas.2013.09.007

Unmack, J. (1990). The fluoroquinolone antibacterial agents. J. R. Austral. Nurs. Federat. 19:28.

U. S. Food and Drug Administration. (2003). Bioavailability and Bioequivalence Studies for Orally Administered Drug Products-General Considerations. U. S. Food and Drug Administration. Available online at: https://www.ipqpubs.com/ wp-content/uploads/2014/04/BABEOld.pdf
Vătășescu, A., Enache, F., Mircioiu, C., Miron, D. S., and Sandulovici, R. (2011). Failure of statistical methods to prove bioequivalence of meloxicam drug products. I. parametric methods. Farmacia 59, 161-171.

Walther, F. M., Allan, M. J., Roepke, R. K., and Nuernberger, M. C. (2014). Safety of fluralaner chewable tablets (Bravecto), a novel systemic antiparasitic drug, in dogs after oral administration. Parasit. Vectors 7:87. doi: 10.1186/1756-3305-7-87

Waxman, S., Rodríguez, C., González, F., De Vicente, M. L., Andrés, M. I. S., and Andrés, M. D. S. (2001). Pharmacokinetic behavior of marbofloxacin after intravenous and intramuscular administrations in adult goats. $J$. Vet. Pharmacol. Therapeut. 24, 375-378. doi: 10.1046/j.1365-2885.2001. 00357.x

Yang, Q., and Hu, Q. (2006). Pharmacokinetics and bioavailability of acyclovir sustained-release tablets in dogs. Eur. J. Drug Metab. Pharmacokinet. 31, 17-20. doi: 10.1007/BF03190637

Yohannes, S., Awji, E. G., Lee, S. J., and Park, S. C. (2015). Pharmacokinetics and pharmacokinetic/pharmacodynamic integration of marbofloxacin after intravenous and intramuscular administration in beagle dogs. Xenobiotica 45, 264-269. doi: 10.3109/00498254.2014.969794

Zaid, A. N., Mousa, A., Jaradat, N., and Bustami, R. (2017). Lornoxicam immediate-release tablets: formulation and bioequivalence study in healthy mediterranean volunteers using a validated LC-MS/MS method. Clin. Pharmacol. Drug Dev. 6, 564-569. doi: 10.1002/cpdd.333

Conflict of Interest Statement: The authors declare that the research was conducted in the absence of any commercial or financial relationships that could be construed as a potential conflict of interest.

Copyright (c) 2018 Lei, Liu, Yang, Khaliq, Ahmed, Fan, Cao and He. This is an open-access article distributed under the terms of the Creative Commons Attribution License (CC BY). The use, distribution or reproduction in other forums is permitted, provided the original author(s) and the copyright owner(s) are credited and that the original publication in this journal is cited, in accordance with accepted academic practice. No use, distribution or reproduction is permitted which does not comply with these terms. 